\title{
Fabrication of a NiFe Alloy Oxide Catalyst via Surface Reconstruction for Selective Hydrodeoxygenation of Fatty Acid to Fatty
} Alcohol

\author{
Depeng Han ${ }^{\dagger}$, Wang Yin ${ }^{\ddagger}$, Shengping Wang ${ }^{\dagger, \S}$, Shuqian Xia ${ }^{*}, \dagger$
}

${ }^{\dagger}$ Affiliation 1: Key Laboratory for Green Chemical Technology of State Education

Ministry, School of Chemical Engineering and Technology, Tianjin University, Tianjin 300350, China

${ }^{\ddagger}$ Affiliation 2: Department of Chemical Engineering, ENTEG, University of

Groningen, Nijenborgh 4, 9747 AG Groningen, The Netherlands

${ }^{\S}$ Affiliation 3: Collaborative Innovation Center of Chemical Science and Engineering (Tianjin), Tianjin 300072, China

* Correspondence: shuqianxia@tju.edu.cn

Number of pages: 8

Number of figures: 6

Number of tables: 2 
Table S1 Content of metallic element in the reduced NiFe AC by ICP-OES

\begin{tabular}{ccc}
\hline & $\mathrm{Ni}, \mathrm{wt} \%$ & $\mathrm{Fe}, \mathrm{wt} \%$ \\
\hline Content & 6.92 & 2.18 \\
\hline
\end{tabular}

Table S2 Effect Bader charge of the atoms in $\mathrm{xO} / \mathrm{NiFe}{ }^{\mathrm{a}}$.

\begin{tabular}{ccccc}
\hline & $\mathrm{Ni}^{\mathrm{b}}$ & $\mathrm{Fe}^{\mathrm{b}}$ & $\mathrm{O}_{\text {total }}{ }^{\mathrm{c}}$ & $\mathrm{O}_{\text {average }}{ }^{\mathrm{d}}$ \\
\hline $\mathrm{NiFe}$ & 0.253 & -0.220 & - & - \\
$1 \mathrm{O} / \mathrm{NiFe}$ & 0.180 & -0.261 & 0.907 & 0.907 \\
$2 \mathrm{O} / \mathrm{NiFe}$ & 0.105 & -0.301 & 1.822 & 0.911 \\
$3 \mathrm{O} / \mathrm{NiFe}$ & 0.040 & -0.344 & 2.664 & 0.888 \\
$4 \mathrm{O} / \mathrm{NiFe}$ & -0.033 & -0.389 & 3.614 & 0.904 \\
$8 \mathrm{O} / \mathrm{NiFe}$ & -0.312 & -0.480 & 6.376 & 0.797 \\
\hline
\end{tabular}

${ }^{\mathrm{a}}, \mathrm{x}$ in the $\mathrm{xO} / \mathrm{NiFe}$ is the number of $\mathrm{O}$ atom adsorbed on the $\mathrm{NiFe}(101)$.

${ }^{\mathrm{b}}$, Average effect Bader charge of the $\mathrm{Ni}$ and Fe on the top most layer.

c, Total Bader charge of all the adsorbed $\mathrm{O}$ atoms.

${ }^{\mathrm{d}}$, Average Bader charge of $\mathrm{O}$ atoms. 


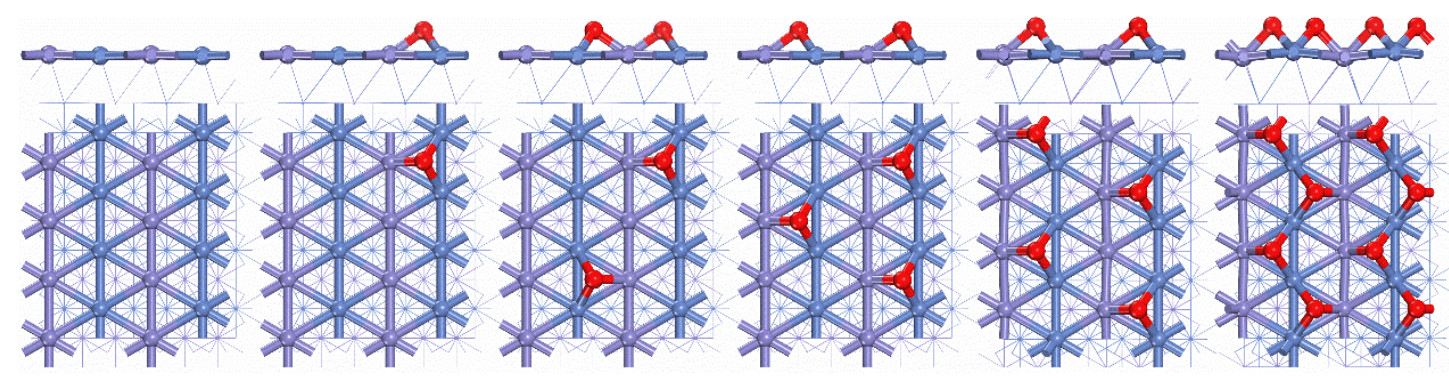

Figure S1 The most stable configurations of the NiFe (101) surfaces after the adsorption of $\mathrm{O}$ atoms.

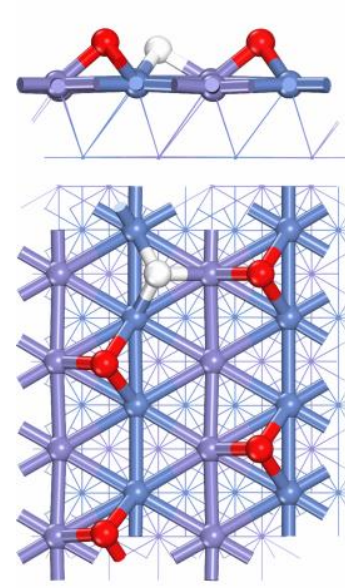

$-3.93$

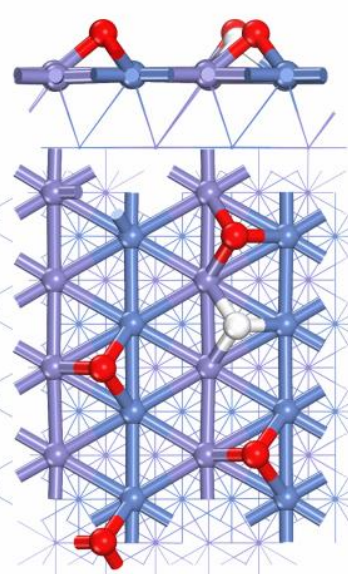

$-4.03$

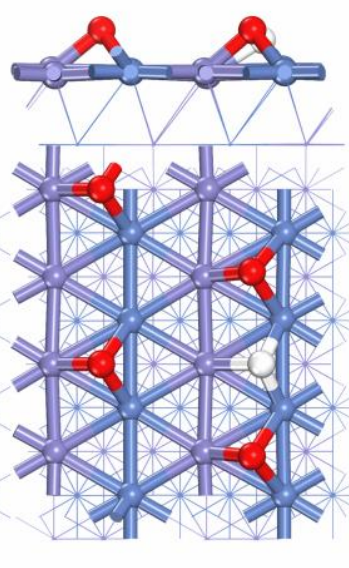

$-3.73$

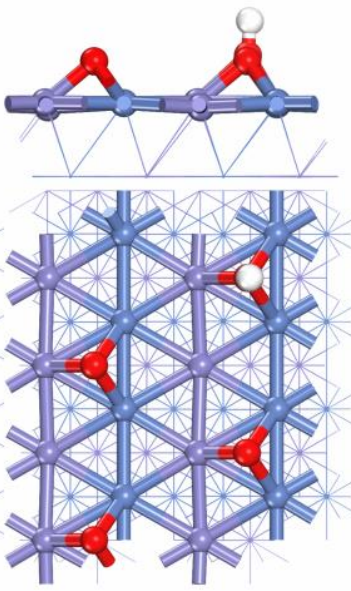

$-3.81$

Figure S2 Different adsorption configurations of $\mathrm{H}$ on $4 \mathrm{O} / \mathrm{NiFe}$ and the corresponding adsorption energy $\left(E_{a d s}\right)$. 

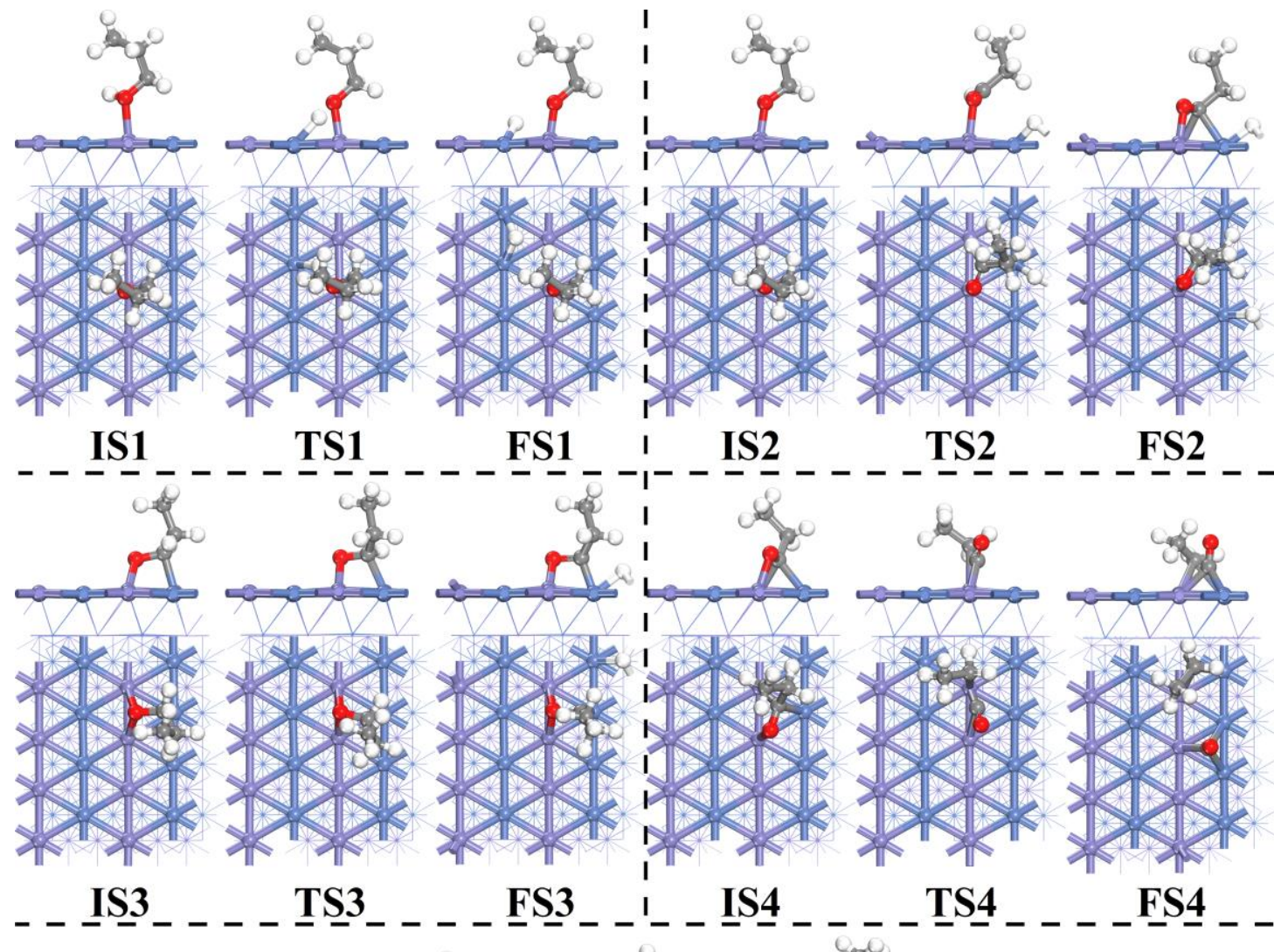

I IS

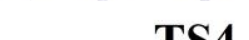

FS4
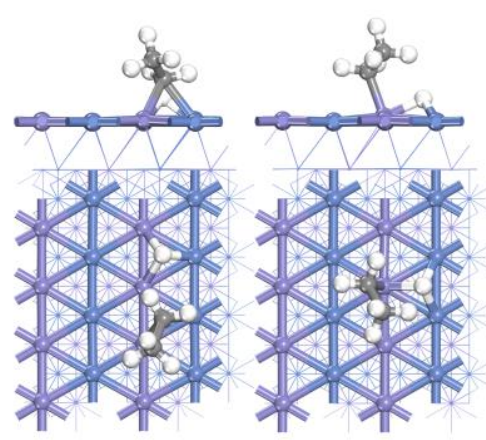

\%

IS5

TS5

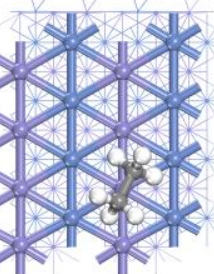

FS5

(a) 


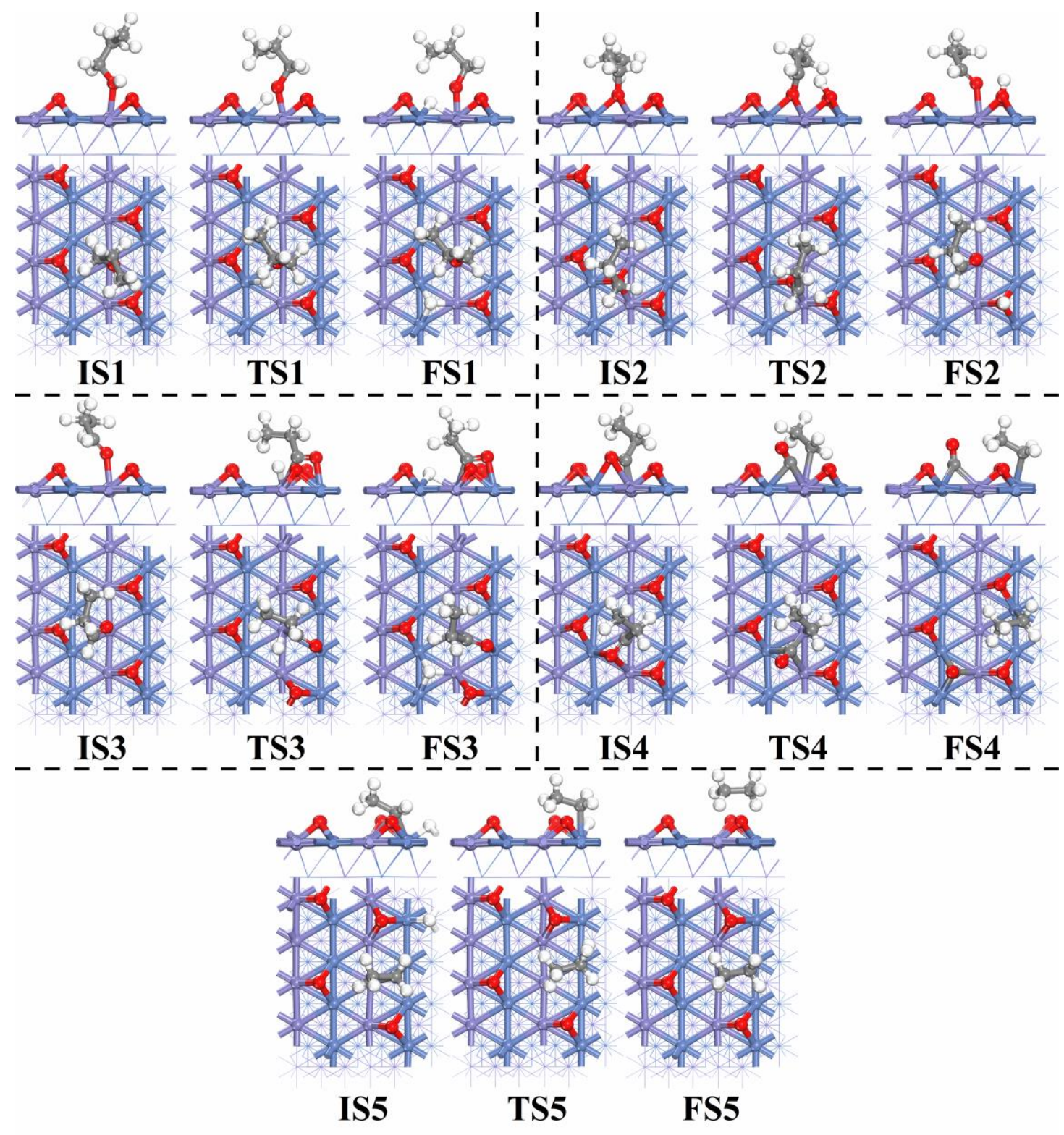

(b)

Figure S3 Initial state (IS), transient state (TS), and final state (FS) configurations of the 5 elementary steps in the decarbonylation of propyl alcohol on (a) $\mathrm{NiFe}$ and (b) 4O/NiFe slab. 


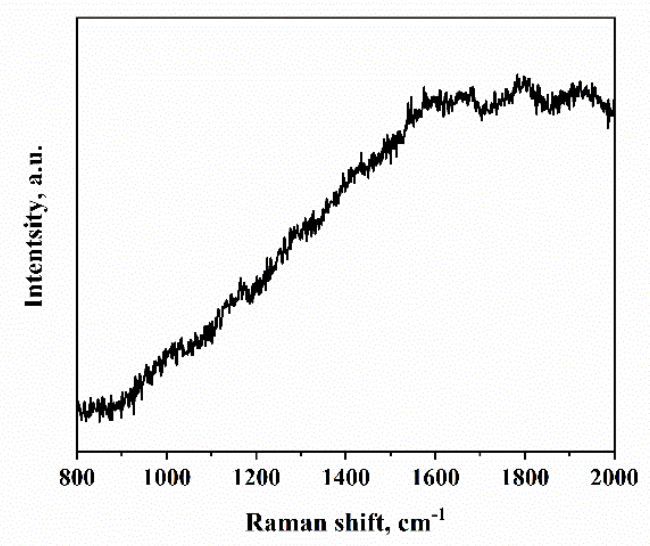

Figure S4 Raman spectra of the O400 that have been used for 6 times.

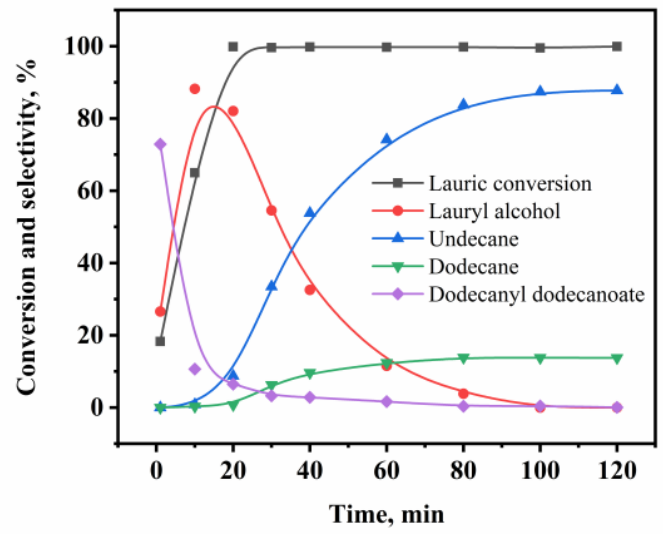

Figure S5 Effect of reaction time on the conversion of lauric acid and product selectivity with reduced $\mathrm{Ni}_{3} \mathrm{Fe}_{1} / \mathrm{SiO}_{2}$ in reference. ${ }^{1}$ Copyright 2021 Elsevier.

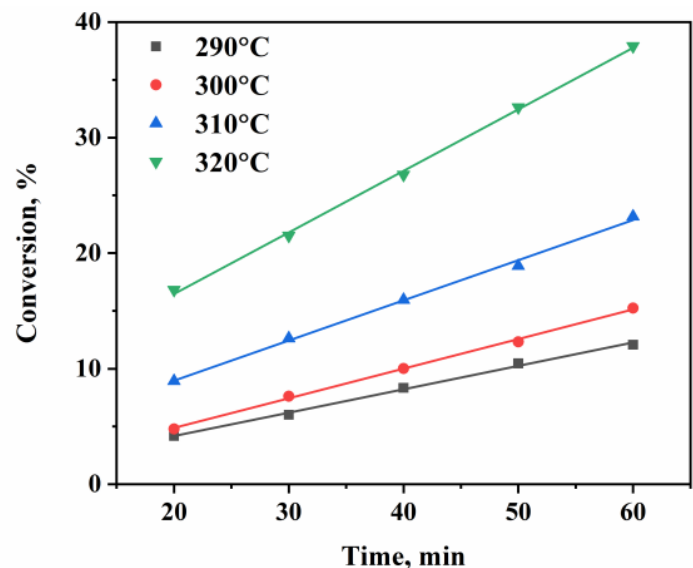

(a)

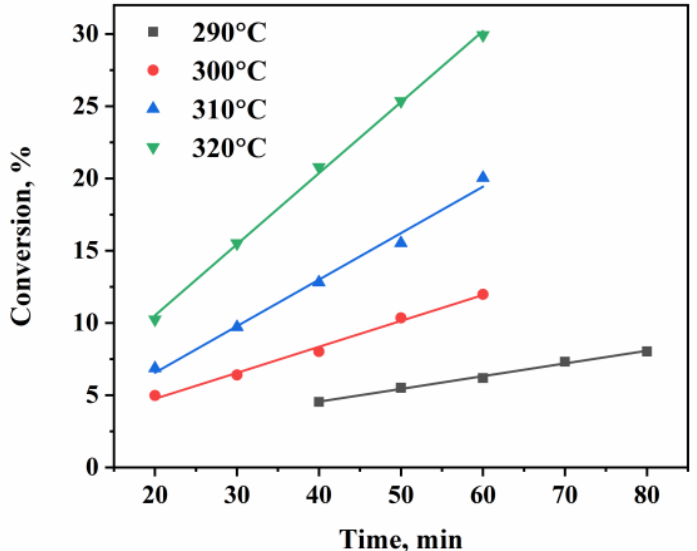

(b) 
Figure S6 Conversion of lauryl alcohol over (a) R700 and (b) O400 catalysts with different reaction time and temperature 


\section{References}

(1) Han, D.; Yin, W.; Luo, D.; He, H.; Wang, S.; Xia, S. Hydrodeoxygenation of Aliphatic Acid over NiFe Intermetallic Compounds: Insights into the Mechanism via Model Compound Study. Fuel 2021, 305 (June), 121545. https://doi.org/10.1016/j.fuel.2021.121545. 